\title{
Pulmonary embolism in transit
}

\author{
Anna Koulova ${ }^{1}$, Ramin Malekan ${ }^{2}$, Wilbert S. Aronow ${ }^{1}$, Howard A. Cooper ${ }^{1}$ \\ ${ }^{1}$ Division of Cardiology, Department of Medicine, Westchester Medical Center and New York Medical College, Valhalla, NY, USA; ${ }^{2}$ Division of \\ Cardiothoracic Surgery, Westchester Medical Center and New York Medical College, Valhalla, NY, USA \\ Correspondence to: Wilbert S. Aronow, MD, FACC, FAHA. Professor of Medicine, Cardiology Division, Westchester Medical Center and New York \\ Medical College, Macy Pavilion, Room 141, Valhalla, NY 10595, USA. Email: wsaronow@aol.com.
}

\begin{abstract}
A 65-year-old woman with recently diagnosed ovarian cancer presented with near syncope, tachypnea, and hypoxia. Transthoracic echocardiography revealed a dilated and hypokinetic right ventricle and a large, mobile mass in the right atrium prolapsing across the tricuspid valve. She was diagnosed with pulmonary embolism in transit and emergent embolectomy was recommended.
\end{abstract}

Keywords: Pulmonary embolism; pulmonary embolectomy; echocardiography; right heart thrombus

Submitted Mar 15, 2017. Accepted for publication Mar 24, 2017.

doi: 10.21037/atm.2017.03.108

View this article at: http://dx.doi.org/10.21037/atm.2017.03.108

\section{Case presentation}

Thromboembolism represents a spectrum of disease from an asymptomatic clot in the lower extremity veins to hemodynamically significant thrombi in the pulmonary arteries. A rare form, only present in 42 of 1,071 patients (3.9\%) with pulmonary embolism followed in a registry study, presents as a thrombus-in-transit through the right heart. Patients with right heart thrombi have nearly double the risk of adverse outcomes ( $>20 \%$ ) compared to others, underscoring the need for prompt diagnosis and treatment (1).

We describe the case of a 65 -year-old woman with a recently diagnosed high grade serous ovarian cancer who underwent debulking surgery 3 months prior to presentation followed by treatment with cisplatin and paclitaxel. She presented with dyspnea and several episodes of near syncope. She was found to be tachypneic and hypoxic. Bedside transthoracic echocardiography revealed a dilated and hypokinetic right ventricle. A large, serpiginous, highly mobile mass was seen within the right atrium which intermittently prolapsed across the tricuspid valve (Figure 1). A diagnosis of pulmonary embolism in transit was made and given the expertise of our center, emergency surgical embolectomy was undertaken. A pooled analysis of 328 patients confirms the efficacy of surgical embolectomy and thrombolysis approaches which were associated with $70.45 \%$ and $81.5 \%$ survival, respectively, in patients with

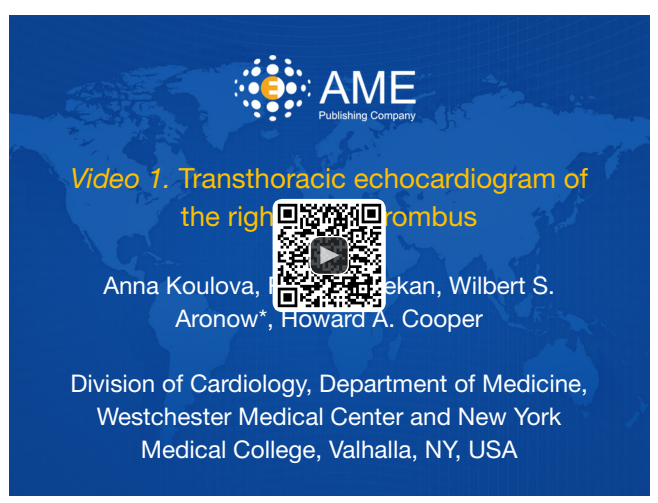

Figure 1 Transthoracic echocardiogram of the right atrial thrombus. The apical four chambers demonstrate a very large, serpiginous, mobile mass within the right atrium, prolapsing through the tricuspid valve. The right ventricle is severely dilated, right ventricular systolic function is severely reduced, and there is paradoxical motion of the interventricular septum (2). Available online: http://www.asvide.com/articles/1524

right heart thrombi (3).

In the operating room, the patient's central venous pressure (CVP) was $23 \mathrm{mmHg}$, and the pulmonary artery (PA) pressure was $47 / 21 \mathrm{mmHg}$. Cardiopulmonary bypass was initiated, and large amounts of clot were retrieved from the right atrium and the left and right pulmonary arteries (Figure 2). Immediately postoperatively, the CVP fell to 


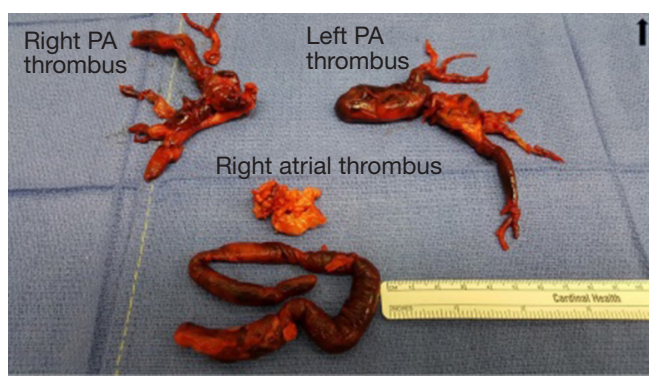

Figure 2 Gross pathological specimen of the thrombus after surgical excision. The specimen consists of irregular fragments of red-tan hemorrhagic soft tissue and blood clots, measuring in aggregate $10.0 \mathrm{~cm} \times 8.0 \mathrm{~cm} \times 2.0 \mathrm{~cm}$. PA, pulmonary artery.

$11 \mathrm{mmHg}$, and the PA pressure fell to $33 / 17 \mathrm{mmHg}$. The patient was easily weaned from cardiopulmonary bypass and was extubated on postoperative day one. Lifelong anticoagulation is planned.

\section{Acknowledgements}

None.

Cite this article as: Koulova A, Malekan R, Aronow WS, Cooper HA. Pulmonary embolism in transit. Ann Transl Med 2017;5(10):209. doi: 10.21037/atm.2017.03.108

\section{Footnote}

Conflicts of Interest: The authors have no conflicts of interest to declare.

Informed Consent: A verbal consent was obtained by Dr. Anna Koulova before the patient moved away.

\section{References}

1. Torbicki A, Galié N, Covezzoli A, et al. Right heart thrombi in pulmonary embolism: results from the International Cooperative Pulmonary Embolism Registry. J Am Coll Cardiol 2003;41:2245-51.

2. Koulova A, Malekan R, Aronow WS, et al. Transthoracic echocardiogram of the right atrial thrombus. Asvide 2017;4:214. Available online: http://www.asvide.com/ articles/1524

3. Athappan G, Sengodan P, Chacko P, et al. Comparative efficacy of different modalities for treatment of right heart thrombi in transit: a pooled analysis. Vasc Med 2015;20:131-8. 